ENCYCLOPÉDIE Encyclopédie berbère

BERBERE

$31 \mid 2010$

31 | Matmora - Mezrag

\title{
Maurétanies (Provinces)
}

\section{Y. Modéran}

\section{OpenEdition}

Journals

Édition électronique

URL : http://journals.openedition.org/encyclopedieberbere/523

DOI : $10.4000 /$ encyclopedieberbere.523

ISSN : 2262-7197

\section{Éditeur}

Peeters Publishers

\section{Édition imprimée}

Date de publication : 30 décembre 2010

Pagination : 4737-4751

ISBN : 978-90-429-2368-3

ISSN : 1015-7344

\section{Référence électronique}

Y. Modéran, « Maurétanies (Provinces) », Encyclopédie berbère [En ligne], 31 | 2010, document M69b, mis en ligne le 08 octobre 2020, consulté le 13 octobre 2020. URL : http://journals.openedition.org/ encyclopedieberbere/523; DOI : https://doi.org/10.4000/encyclopedieberbere.523

Ce document a été généré automatiquement le 13 octobre 2020

(c) Tous droits réservés 


\title{
Maurétanies (Provinces)
}

\author{
Y. Modéran
}

1 Après l'assassinat de Ptolémée*, roi de Maurétanie, dans l'hiver 39-40, l'empereur Caligula ne réussit pas immédiatement à imposer l'autorité romaine aux habitants de cet immense royaume, qui s'étendait de l'Atlantique à l'Ampsaga* (Oued el-Kebir du Constantinois). Certes, l'annexion fut prononcée presque aussitôt, et le $I^{\mathrm{er}}$ janvier 40 devint le premier jour de l'ère provinciale, qui resta en usage jusqu'au VII ${ }^{e}$ siècle (dernière mention à Volubilis en 655 , ou peut-être même plus tard). Mais un affranchi du roi, Aedemon*, prit la tête d'une résistance armée qui ne s'acheva que peu avant la mort de Caligula, en janvier 41. Et après lui, Claude dut envoyer deux expéditions successives en 42 , qui poursuivirent jusque dans l'Atlas des tribus qui résistaient. Ce n'est qu'à ce moment, en 42 , que les territoires annexés furent vraiment divisés et organisés en deux provinces, auxquelles fut donné un nom unique rappelant leur passé maure, avec pour chacune une épithète propre évoquant leur capitale : la Maurétanie Tingitane, dirigée depuis Tingi (Tanger), qui occupait la partie marocaine de l'ancien royaume, jusqu'au fleuve Malva (Moulouya*); et la Maurétanie Césarienne, dirigée depuis Caesarea (Cherchell), qui couvrait l'espace entre la Malva et l'Ampsaga. Toutes les deux reçurent pour gouverneurs des procurateurs équestres, qui eurent en main à la fois l'administration civile et le commandement des troupes, composées en temps normal d'unités auxiliaires et non de légionnaires.

On ignore quasiment tout des limites effectives de l'autorité romaine en Maurétanie Césarienne dans les premières décennies qui suivirent l'annexion. A partir de Trajan, en revanche, la documentation témoigne d'un réel effort de prise en main de régions intérieures essentielles, comme les plaines de Sétif, la vallée du Chélif, et les plaines de l'Oranais, et une grande route militaire fut construite d'est en ouest à partir de Sétif et jusqu'à Albulae (à $70 \mathrm{~km}$ à l'ouest d'Oran, et à moins de $20 \mathrm{~km}$ de la côte). Mais, ainsi agrandi, le territoire provincial de la Césarienne ne représentait encore qu'une bande horizontale le plus souvent éloignée des côtes d'à peine $50 \mathrm{~km}$, et qui enserrait nombre de tribus maures puissantes et agitées. En Tingitane, si la province officielle était très vaste, les régions de contrôle effectif, qui correspondaient aux cités, avaient une physionomie différente, tout en étant finalement aussi restreintes : elles s'étendaient de Tanger à Sala, s'éloignaient jusqu'à $120 \mathrm{~km}$ du rivage atlantique à hauteur de 
Volubilis, le plus souvent moins, et délaissaient non seulement le Haut Atlas, mais aussi l'essentiel du Moyen Atlas et du Rif. Alors qu'à l'est (Tunisie et Algérie orientale), mise en valeur et contrôle militaire et politique atteignirent plus ou moins vite la bordure saharienne, en Maurétanie on en restait donc fort loin. Les choses ne changèrent, de manière encore limitée, que sous les Sévères. Le désir d'ouvrir aux populations romanisées de nouvelles terres qui étaient cultivables, associé à la volonté de briser l'agitation des tribus des massifs situés au sud de la province (comme l'Ouarsenis) et de mieux contrôler les mouvements des pasteurs transhumants et des nomades, décida en effet Septime Sévère (193-211), le premier empereur d'origine africaine, à étendre vers les régions méridionales les limites de la Maurétanie Césarienne. Une nouvelle route militaire (la nova praetentura) fut donc construite entre 198 et 203, de 50 à $100 \mathrm{~km}$ plus au sud que la précédente, jalonnée de nouveaux forts, de Macri (à $100 \mathrm{~km}$ au sud de Sétif) jusqu'à Numerus Syrorum (à $30 \mathrm{~km}$ à l'ouest de l'actuelle Tlemcen). Cette extension territoriale, qui représenta presque un doublement de la surface de la province, s'accompagna de transferts de populations depuis l'Afrique Proconsulaire, comme en témoigne une inscription découverte à Usinaza (100 km au sud d'Alger). Un véritable Far-West africain naquit ainsi sous la dynastie sévérienne, sans bouleverser réellement la répartition du peuplement et l'économie de l'Afrique romaine.

Quelle que fût sa portée effective, la conquête ainsi réalisée fut durable. Les frontières des Maurétanies ne furent plus guère modifiées après Septime Sévère. Seule la Maurétanie Tingitane, probablement sous la pression des tribus maures, fut réduite sous Dioclétien (284-305), en perdant sa moitié méridionale (dont Volubilis). Le reste, sauf peut-être en Césarienne centrale à la fin du IV siècle, resta inchangé jusqu'à l'invasion vandale de 429. Le Bas-Empire marqua cependant un changement important dans l'administration des Maurétanies. Tout d'abord, comme partout dans l'Empire, le nombre des provinces fut augmenté sous Dioclétien, par un rédécoupage en unités plus petites. Une Maurétanie Sitifienne, centrée sur Sitifis (Sétif), fut ainsi créée en 303 aux dépens de la Maurétanie Césarienne : elle couvrit le territoire compris entre l'Oued Soummam et l'Oued el-Kébir. Les gouverneurs des trois provinces, désormais en principe appelés praeses, étaient théoriquement chargés des seules affaires civiles, tandis que le commandement des troupes allait à des officiers autonomes, portant le titre de dux. Toutefois, en Césarienne, le même homme cumula souvent les deux fonctions. Par ailleurs, dès le règne de Dioclétien aussi, les deux Maurétanies Césarienne et Sitifienne furent intégrées à une nouvelle unité administrative, le diocèse d'Afrique, tandis que la Tingitane était placée désormais dans le diocèse d'Espagne. La séparation fut aggravée peu après la mort de Constantin (337) lorsque fut définitivement mis en place un échelon encore supérieur, la préfecture du prétoire : Espagne et Tingitane furent rattachées à la préfecture des Gaules, tandis que la Césarienne et la Sitifienne, comme leurs voisines orientales, furent insérées dans la " préfecture d'Italie, Illyricum et Afrique ».

Cette division des Maurétanies reflétait une différence probablement très ancienne entre la Tingitane et le bloc Césarienne/Sitifienne, due pour la première à des conditions naturelles particulières, mais aussi à des circuits d'échanges tournés plus vers l'Espagne que vers l'Italie. L'absence d'une liaison routière permanente et sécurisée avec la Césarienne encourageait aussi cette distinction, que Dioclétien et Constantin ne firent donc qu'entériner en rattachant la Tingitane à la péninsule ibérique. 
5 Un point commun fort rapprochait en revanche Tingitane et Césarienne, et faisait de manière générale la spécificité des provinces maurétaniennes dans l'Empire: l'importance des tribus (gentes) maures qui y étaient enclavées ou en étaient voisines. Ptolémée au milieu du second siècle en cite dix-sept en Tingitane et vingt-cinq en Césarienne. Les mieux connues sont dans la première de ces provinces les Baquates*, les Macénites*, et les Zegrenses*, et en Césarienne les Mazices*, les Bavares*, et les Quinquegentiani* (ces deux derniers groupes seulement à partir du III ${ }^{\mathrm{e}}$ siècle). La localisation précise de ces gentes n'est toutefois pas toujours très claire, et leur insertion effective dans la province reste parfois très discutée, notamment dans le cas des Baquates. Certaines semblent avoir été administrativement rattachées à des cités, par la procédure romaine d'adtributio. D'autres, jugées suspectes ou instables, étaient dirigées par un praefectus gentis* nommé par l'empereur, souvent recruté parmi les officiers de l'armée au Haut-Empire, puis de plus en plus parmi les notables de la gens au $\mathrm{IV}^{\mathrm{e}}$ siècle. La majorité des tribus provinciales disposaient d'une réelle autonomie, avec à leur tête des chefs coutumiers qui étaient investis officiellement par l'autorité romaine, dont ils reconnaissaient formellement la souveraineté, et dont ils recevaient aussi parfois le statut de citoyen romain (cf. la célèbre table de Banasa).

6 Malgré cette relative souplesse du contrôle romain, d'importantes insurrections éclatèrent à plusieurs reprises, notamment dans les années 140 sous Antonin le Pieux, entre 263 et 262, dans les années 290, et enfin entre 370 et 375 (révolte de Firmus*). Toute la question, encore aujourd'hui non résolue, est de savoir si ces troubles furent les moments d'apogée d'un état d'agitation endémique (Benseddik, 1982), ou au contraire des phénomènes conjoncturels isolés (Frezouls, 1980). Nos sources sont trop fragmentaires pour qu'une conclusion nette s'impose. Il est sûr que les tribus qui vivaient à l'intérieur du territoire provincial étaient familières de la romanité, ne serait-ce que par le contrôle militaire subi, le paiement des impôts, et l'investiture de leurs chefs. Une prospection archéologique minutieuse dans l'arrière-pays de Cherchell (Leveau, 1984) a montré qu'elles recevaient aussi, à un degré plus ou moins limité, des marchandises des villes. Certains de leurs chefs, au IV ${ }^{\mathrm{e}}$ siècle, furent intégrés aux élites provinciales, en se dotant de grands domaines de type romain, et en recevant parfois, comme Gildon*, frère de Firmus devenu comte d'Afrique vers 385, des fonctions officielles dans l'Etat romain. Mais tout ceci ne prouve pas, pour les masses, une pleine adhésion aux valeurs de la romanité et une acceptation des rapports de force institués par l'Empire.

7 Le problème essentiel qui se pose aux historiens est, au total, de savoir si ces Maurétanies constituaient des provinces vraiment particulières, un peu à part, ou si les similitudes avec le reste de l'Afrique dominaient. Il est d'usage depuis une trentaine d'années de les présenter séparément (Lepelley, 1979), et de parler de « deux Afriques romaines ". L'idée, à dire vrai, n'est pas neuve, et était déjà implicite en 359 chez l'auteur de l'Expositio totius mundi etgentium (LX), lorsqu'il disait du «pays de Maurétanie » que «ses habitants ont une vie et des mœurs de barbares, quoique sujets des Romains ». Elle se justifie, à la condition de ne pas faire des Maurétanies des quatre premiers siècles de notre ère la préfiguration de ce que Christian Courtois (1955) appelait «l'Afrique abandonnée». Car s'il est indéniable qu'elles connurent globalement une urbanisation éparse, laissant place à d'importants groupements tribaux berbères, et que la présence de l'armée, notamment en Tingitane, y fut plus visible qu'ailleurs, elles virent aussi naître une romanité originale, dont on ne saurait 
négliger la richesse et la grandeur. Sans parler de certaines productions spécifiques (comme la pourpre), le garum et les salaisons de Tingitane ou l'huile de Césarienne étaient aussi connus et appréciés dans le monde méditerranéen que ceux de Byzacène. Et Volubilis, Caesarea, Tipasa ou Sitifis furent de belles et brillantes cités, où s'épanouit une civilisation aux réalisations comparables à celles de bien des villes de l'Occident romain. Ce n'est donc probablement pas sans raison que lorsque Rome perdit définitivement le contrôle de ces provinces, après 455 , les princes maures qui s'en emparèrent s'efforcèrent de conserver l'héritage romain, comme l'atteste le titre de « rex gentium Maurorum et Romanorum. » adopté par le roi Masuna*. La Maurétanie ne voulait peut-être pas être appelée Afrique, comme disait saint Augustin (Lettre 93, 8, 24), mais ses provinces furent bien romaines.

\section{BIBLIOGRAPHIE}

Le genre ayant été très délaissé par l'historiographie moderne depuis 1945, il n'existe aucune monographie de synthèse récente sur ces provinces. On rappellera cependant l'existence de trois vieux ouvrages :

CAT E., Essai sur la province romaine de Maurétanie Césarienne, Paris, 1891.

CARCOPINO J., Le Maroc antique, Paris, 1943.

CHATELAIN L., Le Maroc des Romains, Paris, 1944

Travaux de synthèse plus récents :

BENABOU M., La résistance africaine à la romanisation, Paris, 1976, réimp. Paris, 2005.

BENSEDDIK N., Les troupes auxiliaires de l'armée romaine en Maurétanie Césarienne sous le Haut-Empire, Alger, 1982.

COURTOIs C., Les Vandales et l'Afrique, Paris, 1955.

FREZOULS E., « Rome et la Maurétanie Tingitane : un constat d'échec ? », Antiquités africaines, 16, 1980 , p. 65-93.

HAMDOUNE C., « Les relations entre les deux Maurétanies », L'Africa romana XIV, Rome, 2002, p. 1425-1443.

LANCEL S., L'Algérie antique, Paris, 2003.

LEPELLEY Cl., Les cités de l'Afrique romaine au Bas-Empire, 2 vol., Paris, 1979-1981.

Leveau Ph., Caesarea de Maurétanie : une ville romaine et ses campagnes, Rome, 1984.

POTTER T. W., Towns in Late antiquity: Iol Caesarea and its Context, Londres, 1995.

REBUFFAT R., « Enceintes urbaines et insécurité en Maurétanie Tingitane », MEFRA, 86, 1974, p. 501-522.

REBUFFAT R., « La frontière de la Tingitane », dans Cl. Lepelley et X. Dupuis, Frontières et limites géographiques de l'Afrique du Nord antique. Hommage à Pierre Salama, Paris, 1999, p. 265-293. 
INDEX

Mots-clés : Anthropologie, Antiquité, Histoire, Histoire politique, Maurétanie 